DOI : https://doi.org/10.24843/JFU.2020.v09.i01.p03

pISSN: 2301-7716; eISSN: 2622-4607

Jurnal Farmasi Udayana, Vol 9, No 1, Tahun 2020, 19-25

\title{
Effektivitas dan Biaya pada Terapi Pasien Diabetes Mellitus Tipe 2 Rawat Jalan di Rumah Sakit Umum Denpasar
}

\author{
Sarasmita, M.A. ${ }^{1,2}$, Iswari, W.R. ${ }^{3}$, Deviyanti, I.A.S. ${ }^{3}$, Warnaya, P.C.I. ${ }^{3}$, Candraningrat, I.D.A.A.D. ${ }^{3 *}$, Meryta, \\ L.P.A. ${ }^{3}$, Larasanty, L. P. F. ${ }^{1}$ \\ 1Program Studi Profesi Apoteker, Fakultas Matematika dan Ilmu Pengetahuan Alam, Universitas Udayana, Jalan \\ Kampus Unud, Jimbaran, 80364 \\ 2Program Studi S3 Ilmu Farmasi, Taipei Medical University \\ 3 Program Studi Farmasi, Fakultas Matematika dan Ilmu Pengetahuan Alam, Universitas Udayana, Jalan Kampus \\ Unud, Jimbaran, 80364 \\ *E-mail: ciaintania17@gmail.com
}

Riwayat artikel: Dikirim:17/07/2019; Diterima: 31/03/2020, Diterbitkan: 25/06/2020

\begin{abstract}
Therapy guidelines for patients with type 2 diabetes mellitus emphasize the need for a personal approach in the choose of drug therapy for each patient. This has an implication for the emergence of different therapeutic groups in the treatment of type 2 diabetes mellitus. The purpose of this study is to determine the therapeutic groups of treatment in type 2 diabetes mellitus patients, the total cost therapy, the therapy effectiveness and the ratio between the two. This research is a prospective descriptive study in diabetes mellitus outpatients in Denpasar general hospital which is followed for 3 months continuously. There were 34 patients who met the inclusion and exclusion criteria of the study which were divided into 7 large groups of antidiabetic therapy. The effectiveness of antidiabetic therapy ranges from $11.11 \%$ to $66.66 \%$. The total range of antidiabetic therapy costs ranges from IDR. 548,094 up to IDR. 3,274,372. The therapy group with the lowest cost-per- percent effectiveness ratio was metformin and glimepiride combination therapy with the cost of IDR. 19,184/\% effectiveness and the highest was the combination therapy of Insulin Aspart and Insulin Glargine which was IDR 261,882 /\% effectiveness.
\end{abstract}

Keywords: cost, drug therapy, effectiveness, type 2 diabetes mellitus, outpatient.

Panduan terapi pada pasien diabetes melitus tipe 2 menekankan perlunya pendekatan personal dalam perberian terapi obat pada pasien. Hal ini berimplikasi terhadap munculnya kelompok terapi yang berbeda dalam penanganan diabetes melitus tipe 2. Tujuan penelitian ini adalah untuk mengetahui kelompok - kelompok terapi pada penanganan pasien diabetes mellitus tipe 2, total biaya terapi, effektivitas terapi dan rasio diantara keduanya. Penelitian ini merupakan penelitian deskriptif prospektif pada pasien diabetes mellitus rawat jalan di rumah sakit umum Denpasar yang diikuti selama 3 bulan secara terus menerus. Terdapat 34 pasien yang memenuhi kriteria inklusi dan ekslusi penelitian yang terbagi menjadi 7 kelompok besar terapi antidiabetes. Effektivitas terapi antidiabetik berkisar antara $11,11 \%$ sampai dengan $66,66 \%$. Rentang total biaya terapi antidiabetik berkisar antara Rp. 548.094,- sampai dengan Rp. 3.274.372,-. Kelompok terapi dengan rasio biaya per persen effektivitas terendah adalah terapi kombinasi metformin dan glimepiride yaitu dengan biaya $\mathrm{Rp}$ 19.184/\% effektivitas dan yang tertinggi adalah terapi kombinasi Insulin Aspart dan Insulin Glargine yaitu Rp. 261.882/\% effektivitas.

Kata kunci: biaya, diabetes mellitus tipe 2, effektivitas, rawat jalan, terapi obat. 
DOI : https://doi.org/10.24843/JFU.2020.v09.i01.p03

pISSN: 2301-7716; eISSN: 2622-4607

Jurnal Farmasi Udayana, Vol 9, No 1, Tahun 2020, 19-25

\section{PENDAHULUAN}

Diabetes mellitus tipe 2 (DM tipe 2) merupakan masalah kesehatan utama di seluruh dunia dan memiliki prevalensi yang terus meningkat. Saat ini DM tipe 2 mempengaruhi lebih dari 400 juta orang di seluruh dunia, dan pada tahun 2040, diperkirakan akan ada lebih dari 640 juta orang yang menderita DM tipe 2 diseluruh dunia (Penalver et al., 2016). Diabetes mellitus tipe 2 adalah penyakit yang relatif sulit untuk ditangani. Sebagian besar pedoman klinis internasional merekomendasikan pendekatan individual dalam pengelolaan DM tipe 2 dengan pencapaian target HbA1c optimal pada masing masing pasien (Downes et al., 2015).

Laporan konsensus dari American Diabetes Association (ADA) dan the European Association for the Study of Diabetes (EASD) memberikan panduan terapi bagi penanganan hiperglikemia pada pasien DM tipe 2. Terdapat 2 golongan besar terapi obat pada penanganan pasien DM tipe 2 yaitu antidiabetik oral dan obat - obat injeksi seperti insulin. Pemilihan jenis obat direkomendasikan disesuaikan dengan kondisi masing - masing pasien (Davies et al., 2018). Dengan demikian akan banyak sekali pola terapi obat yang dapat ditemukan dalam pelayanan kesehatan bagi pasien DM tipe 2 .

Perbedaan pola terapi obat ini nantinya akan berpengaruh pada respon pasien terhadap pengobatan yang dapat dinilai dengan effektivitas terapi (Downes et al., 2015; Davies et al., 2018). Effektivitas terapi berdasarkan konsensus perkumpulan endrokrinologi Indonesia (Perkeni) dinilai dari pencapaian nilai gula darah puasa (GDP) $80-130 \mathrm{mg} / \mathrm{dl}$, nilai gula darah 2 jam post prandial (GD2PP) $<180 \mathrm{mg} / \mathrm{dl}$ dan nilai HbA1c $<7 \%$ (PERKENI, 2015). Perbedaan regimen terapi tiap pasien juga dapat mempengaruhi besaran biaya yang dikeluarkan pasien untuk memperoleh terapi untuk penyakitnya. Penghitungan besaran biaya dapat berupa biaya medis maupun biaya non medis (Direktorat Jendral Bina Kefarmasian, 2013).

Penelitian ini bertujuan untuk mengetahui kelompok terapi obat antidiabetes yang digunakan pada pasien rawat jalan di rumah sakit umum yang tersebar di Kota Denpasar. Serta untuk mengetahui bagaimana effektivitas kelompok terapi tersebut serta biaya yang harus dikeluarkan untuk terapi antidiabetes yang diperoleh pasien. Dengan demikian akan memberikan gambaran terhadap besaran rasio biaya terhadap effektivitas yang diperoleh pada masing - masing kelompok obat antidiabetes.

\section{BAHAN DAN METODE}

\section{Alat dan Bahan \\ Alat}

Lembar pengumpul data, kuisioner riwayat sosial pasien, dan inform consent.

\section{Bahan}

Rekam medis pasien, rekam pengobatan pasien, lembar administrasi pasien, lembar resep, kartu obat pasien, petikan gaji terakhir pasien, daftar peralatan penunjang medis pasien.

\section{Metode}

Penelitian ini merupakan penelitian deskriptif yang dilakukan secara prospektif. Rancangan penelitian deskriptif karena menggambarkan secara sistematis data yang diteliti setelah penelitian secara tepat. Bersifat prospektif karena data penelitian diambil ketika penelitian sedang berlangsung. Studi follow up dilakukan dengan memantau profil glukosa darah pasien DM tipe 2 setiap bulan selama 3 bulan yang meliputi GDP, GD2PP dan HbA1c.

\section{Tempat dan waktu penelitian}

Penelitian dilakukan di 3 rumah sakit umum yang berada di Kota Denpasar selama tahun 2017. Pelaksanaan penelitian dinyatakan layak etik dan telah mendapatkan ethical clearance dengan nomor 105/UN14.2/KEP/2017, nomor 107/UN14.2/KEP/2017 dan nomor 162/UN14.2/KEP/2017.

\section{Kriteria inklusi dan eksklusi pasien}

Kriteria inklusi pasien meliputi pasien dengan usia lebih besar atau sama dengan 20 tahun, memiliki kadar glukosa darah puasa $>126$ $\mathrm{mg} / \mathrm{dL}$ atau kadar HbA1c $>6,5 \%$, bersedia ikut dalam penelitian (menandatangani lembar informed consent) dan mendapatkan terapi antidiabetik oral tunggal atau terapi antidiabetik oral kombinasi atau terapi kombinasi insulin dan antidiabetik oral atau terapi insulin tunggal maupun kombinasi dari awal bulan (baseline) hingga bulan 3 tanpa adanya 
perubahan jenis obat yang digunakan. Kriteria ekslusi pasien adalah pasien DM tipe 2 yang sedang hamil atau menyusui, pasien yang menggunakan kontrasepsi oral dan obat - obat lainnya yang dapat mempengaruhi kadar glukosa darah pasien seperti loop diuretik, thiazide dan kortison, pasien DM tipe 2 dengan penyakit penyerta seperti penyakit jantung koroner, gangguan fungsi hati dan ginjal dan pasien mengalami perubahan jenis terapi antidiabetik selama periode terapi.

\section{Pengambilan data pasien}

Pasien yang memenuhi kriteria inklusi dan eksklusi di follow up selama 3 bulan untuk mendapatkan data demografi, data GDP, GD2PP dan HbA1c pada bulan ke 0 (baseline) sampai dengan bulan ke 3. Data biaya terapi yang diambil adalah biaya medis langsung, biaya non medis langsung dan biaya non medis tidak langsung. Biaya medis langsung meliputi biaya obat antidiabetes, biaya obat tambahan (untuk penyakit penyerta atau komplikasi), biaya pemeriksaan laboratorium dan biaya jasa tenaga kesehatan. Biaya non medis langsung yang diambil adalah biaya transportasi menuju dan dari fasilitas perawatan kesehatan, dan perjalanan tambahan menuju ruang emergensi, serta makanan khusus. Sedangkan biaya non medis tidak langsung yang diambil adalah biaya yang diperoleh dari hilangnya produktivitas (tidak masuk kerja) (Shanchez, 2008).

\section{Analisa data}

Analisa deskritif dilakukan pada data demografi pasien, data baseline profil glukosa darah pasien, nilai glukosa darah puasa, glukosa darah sewaktu dan glukosa darah postprandial, nilai $\mathrm{HbA1c}$ dan total biaya terapi. Effektivitas terapi dihitung berdasarkan Persentase jumlah pasien yang dapat mencapai target terapi berdasarkan hasil Konsensus Perkeni tahun 2015 dibandingkan jumlah seluruh pasien dalam satu kelompok terapi. Rasio effektivitas biaya dihitung dengan membandingkan total biaya terapi dengan Persentase effektivitas terapi pada masing masing kelompok terapi. Analisa statistik dilakukan untuk melihat apakah terdapat perbedaan secara statistik antara pencapaian target terapi antar pasien di dalam satu kelompok terapi.

\section{HASIL}

Tabel 1. Data karakteristik pasien diabetes mellitus tipe 2 rawat jalan di rumah sakit umum Denpasar.

\begin{tabular}{|c|c|c|c|}
\hline No. & Karakteristik Pasien & Jumlah (n) & $(\%)$ \\
\hline \multirow[t]{3}{*}{1.} & Jenis Kelamin & & \\
\hline & Laki - laki & 17 & 50,00 \\
\hline & Perempuan & 17 & 50,00 \\
\hline \multirow[t]{4}{*}{2.} & Usia & & \\
\hline & $30-44$ tahun & 10 & 29,41 \\
\hline & $45-60$ tahun & 17 & 50,00 \\
\hline & $61-75$ tahun & 7 & 20,59 \\
\hline \multirow[t]{6}{*}{3.} & Pekerjaan & & \\
\hline & PNS & 8 & 23,53 \\
\hline & Wiraswasta & 7 & 20,59 \\
\hline & Pensiunan & 5 & 14,71 \\
\hline & IRT & 13 & 38,23 \\
\hline & Tidak bekerja & 1 & 2,94 \\
\hline \multirow[t]{11}{*}{4.} & Kelompok Terapi Obat Antidiabetes & & \\
\hline & Metformin & 3 & 8.82 \\
\hline & Kombinasi Metformin dan Glimepirid & 7 & 20.59 \\
\hline & Kombinasi 70 \% Insulin Aspart Protamin, $30 \%$ Insulin & & \\
\hline & Aspart dan Metformin & 3 & 8.82 \\
\hline & Kombinasi Insulin Aspart, Insulin Glargine dan & & \\
\hline & Metformin & 3 & 8.82 \\
\hline & Kombinasi Insulin Glargine dan Metformin & 4 & 11.77 \\
\hline & Kombinasi Insulin Aspart dan Insulin Glargine & 9 & 26.47 \\
\hline & Kombinasi $70 \%$ Insulin Aspart Protamin dan $30 \%$ & & \\
\hline & Insulin Aspart & 5 & 14.71 \\
\hline
\end{tabular}


Sarasmita dkk.

DOI : https://doi.org/10.24843/JFU.2020.v09.i01.p03

pISSN: 2301-7716; eISSN: 2622-4607

Jurnal Farmasi Udayana, Vol 9, No 1, Tahun 2020, 19-25

Total jumlah pasien yang memenuhi kriteria inklusi dan eksklusi penelitian berjumlah 34 orang pasien. Sebagian besar pasien dengan diagnosa DM tipe 2 tidak memenuhi kriteria inklusi karena

mengalami komplikasi yang serius atau mendapatkan perubahan jenis terapi selama 3 bulan follow up penelitian. Data karakteristik pasien dapat dilihat pada tabel 1.

Tabel 2. Profil gula darah dan nilai HbA1c pasien diabetes mellitus tipe 2 rawat jalan di rumah sakit umum Denpasar.

\begin{tabular}{|c|c|c|c|c|c|c|c|}
\hline \multirow{3}{*}{ No. } & \multirow{3}{*}{ Kelompok Terapi Obat Antidiabetes } & \multicolumn{6}{|c|}{ Profil gula darah dan $\mathrm{HbA1c}$} \\
\hline & & \multicolumn{2}{|c|}{$\begin{array}{l}\text { Gula darah puasa } \\
\qquad(\mathrm{mg} / \mathrm{dl})\end{array}$} & \multicolumn{2}{|c|}{$\begin{array}{l}\text { Gula darah } 2 \mathrm{jam} \\
\text { post prandial }(\mathrm{mg} / \mathrm{dl})\end{array}$} & \multicolumn{2}{|c|}{$\begin{array}{l}\text { Nilai HbA1c } \\
(\%)\end{array}$} \\
\hline & & baseline & bln ke 3 & baseline & bln ke 3 & baseline & bln ke 3 \\
\hline \multirow[t]{3}{*}{1.} & Terapi antidiabetes oral & & & & & & \\
\hline & a. Metformin & 142 & 134 & 179 & 191 & 8,72 & 7,49 \\
\hline & b. Kombinasi Metformin dan Glimepirid & 194 & 171 & 227 & 212 & 9,31 & 8,22 \\
\hline \multirow[t]{7}{*}{2.} & $\begin{array}{l}\text { Terapi kombinasi insulin dan } \\
\text { antidiabetes oral }\end{array}$ & & & & & & \\
\hline & a. Kombinasi 70 \% Insulin Aspart & 231 & 190 & 302 & 261 & 10,23 & 9,74 \\
\hline & $\begin{array}{l}\text { Protamin, } 30 \% \text { Insulin Aspart dan } \\
\text { Metformin }\end{array}$ & & & & & & \\
\hline & b. Kombinasi Insulin Aspart, Insulin & & & & & & \\
\hline & Glargine dan Metformin & 204 & 178 & 295 & 183 & 9,22 & 7,57 \\
\hline & $\begin{array}{l}\text { c. Kombinasi Insulin Glargine dan } \\
\text { Metformin }\end{array}$ & & & & & & \\
\hline & & 202 & 125 & 240 & 182 & 9,30 & 7,60 \\
\hline \multirow[t]{4}{*}{3.} & Terapi insulin & & & & & & \\
\hline & $\begin{array}{l}\text { a. Kombinasi Insulin Aspart dan Insulin } \\
\text { Glargine }\end{array}$ & 189 & 195 & 290 & 239 & 9,68 & 8,36 \\
\hline & b. Kombinasi 70 \% Insulin Aspart & & & & & & \\
\hline & Protamin dan $30 \%$ Insulin Aspart & 158 & 123 & 262 & 224 & 9,17 & 7,5 \\
\hline
\end{tabular}

Tabel 3. Rincian biaya terapi yang dikeluarkan oleh pasien diabetes mellitus tipe 2 rawat jalan di rumah sakit umum Denpasar.

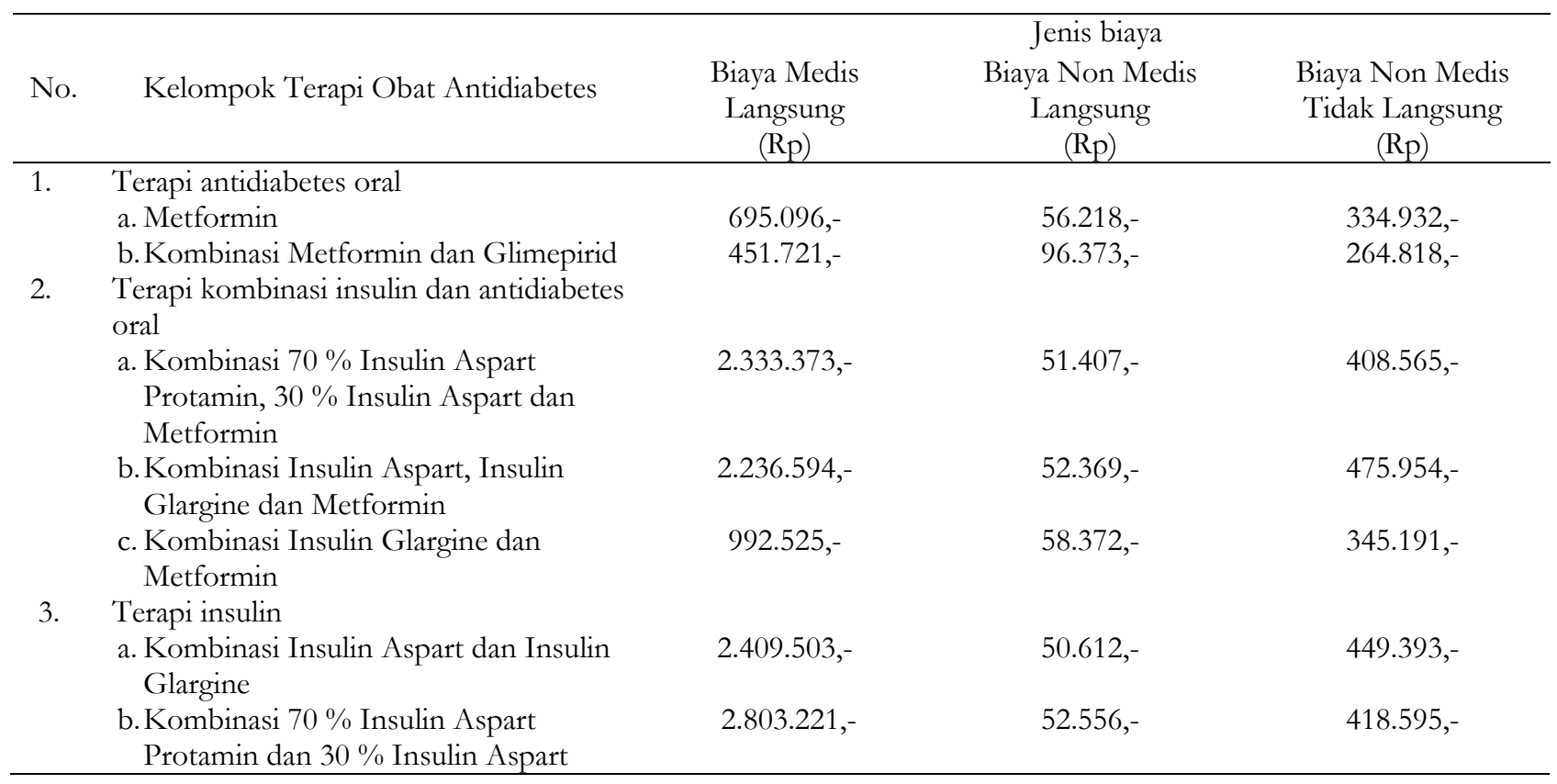


Sarasmita dkk.

DOI : https://doi.org/10.24843/JFU.2020.v09.i01.p03

pISSN: 2301-7716; eISSN: 2622-4607

Jurnal Farmasi Udayana, Vol 9, No 1, Tahun 2020, 19-25

Tabel 4. Rasio effektivitas biaya terapi diabetes mellitus tipe 2 rawat jalan di rumah sakit umum Denpasar.

\begin{tabular}{|c|c|c|c|c|}
\hline No. & Kelompok Terapi Obat Antidiabetes & $\begin{array}{l}\text { Total Biaya } \\
\text { (A) } \\
\text { Rp }\end{array}$ & $\begin{array}{l}\text { Effektivitas terapi } \\
\text { (B) } \\
\%\end{array}$ & $\begin{array}{l}\text { Rasio } \\
(\mathrm{A} / \mathrm{B})^{\mathrm{a}}\end{array}$ \\
\hline 1. & $\begin{array}{l}\text { Terapi antidiabetes oral } \\
\text { a. Metformin } \\
\text { b. Kombinasi Metformin dan } \\
\text { Glimepirid }\end{array}$ & $\begin{array}{c}1.086 .246,- \\
548.094,-\end{array}$ & $\begin{array}{l}33,33 \\
28,57\end{array}$ & $\begin{array}{l}32.591 \\
19.184\end{array}$ \\
\hline 2. & $\begin{array}{l}\text { Terapi kombinasi insulin dan } \\
\text { antidiabetes oral } \\
\text { a. Kombinasi } 70 \% \text { Insulin Aspart } \\
\text { Protamin, } 30 \% \text { Insulin Aspart dan } \\
\text { Metformin }\end{array}$ & 2.793.345,- & 33,33 & 83.809 \\
\hline & $\begin{array}{l}\text { b. Kombinasi Insulin Aspart, Insulin } \\
\text { Glargine dan Metformin } \\
\text { c. Kombinasi Insulin Glargine dan } \\
\text { Metformin }\end{array}$ & $\begin{array}{l}\text { 2.76.4917,-- } \\
\text { 1.396.088,-- }\end{array}$ & 66,66 & 20.943 \\
\hline 3. & $\begin{array}{l}\text { Terapi insulin } \\
\text { a. Kombinasi Insulin Aspart dan } \\
\text { Insulin Glargine }\end{array}$ & $2.909 .508,-$ & 11,11 & 261.882 \\
\hline & $\begin{array}{l}\text { b. Kombinasi } 70 \% \text { Insulin Aspart } \\
\text { Protamin dan } 30 \% \text { Insulin Aspart }\end{array}$ & $3.274 .372,-$ & 20,00 & 163.719 \\
\hline
\end{tabular}

\section{PEMBAHASAN}

Jenis kelamin laki - laki merupakan salah satu faktor resiko kejadian DM tipe 2 (Harreiter and Kautzky, 2018), namun pada penelitian ini diperoleh hasil bahwa jumlah pasien laki - laki dan perempuan memiliki rasio yang sama. Hal ini salah satunya dapat disebabkan karena adanya rentang jarak kelompok usia yang panjang pada subjek penelitian ( $30-75$ tahun). Laki - laki akan terdiagnosa lebih awal mengalami DM tipe 2, sedangkan pada perempuan kejadian DM tipe 2 akan meningkat seiring perubahan/gangguan hormonal. Sehingga umumnya terdiagnosa pada usia yang lebih tua (Harreiter and Kautzky, 2018). Terdapat 3 kelompok besar terapi yang pasien peroleh, yaitu kelompok terapi antidiabetes oral, kelompok terapi kombinasi antara insulin dan antidiabetes oral serta kelompok terapi insulin. Apabila dilihat profil gula darah dan nilai $\mathrm{HbA1c}$ pasien pada tabel 2. Untuk meyakinkan bahwa tidak ada perbedaan data baseline gula darah dan HbA1c pasien pada masing - masing kelompok terapi, dilakukan uji statistik Anova one way. Tidak terdapat perbedaan yang signifikan secara statistik pada nilai baseline antar pasien dalam satu kelompok terapi $(\mathrm{p}>0,05)$. Hal ini menunjukkan bahwa perubahan yang terjadi pada bulan ke 3 disebabkan oleh terapi obat yang diperoleh pasien dan tidak disebabkan karena adanya perbedaan kondisi awal pasien

Kelompok pasien yang mendapatkan terapi antidiabetes oral memiliki rerata baseline nilai GDP, GD2PP dan HbA1c lebih rendah dibandingkan dua kelompok lainnya. Penggunaan obat antidiabetes oral secara monoterapi merupakan terapi lini pertama pada pasien dengan HbA1c $\geq 7,5 \%$. Apabila pasien selama 3 bulan mendapatkan monoterapi namun nilai $\mathrm{HbA1c}$ masih belum mencapai target maka dapat diberikan terapi kombinasi antidabetik oral (PERKENI, 2015; Luna and Feinglos, 2001). Terapi kombinasi insulin dan antidiabetes oral atau terapi insulin baik monoterapi maupun kombinasi beberapa jenis insulin akan diberikan pada pasien dengan nilai HbA1c $>9 \%$ (Luna and Feinglos, 2001; Chaudury et al., 2017). Hal ini sesuai dengan yang terlihat pada hasil penelitian.

Rincian biaya terapi yang dikeluarkan pasien dapat dilihat pada tabel 3. Terlihat bahwa pengeluaran untuk biaya medis langsung merupakan komponen biaya terbesar yang 
DOI : https://doi.org/10.24843/JFU.2020.v09.i01.p03

pISSN: 2301-7716; eISSN: 2622-4607

Jurnal Farmasi Udayana, Vol 9, No 1, Tahun 2020, 19-25

dikeluarkan oleh pasien. Biaya langsung merupakan biaya yang dikeluarkan untuk produk medis dan pelayanan untuk mencegah, deteksi, dan atau menyembuhkan penyakit (Shanchez, 2008). Biaya medis langsung pada kelompok terapi yang mendapatkan insulin jauh lebih besar dibandingkan kelompok terapi yang hanya mendapatkan obat antidiabetes oral. Hal ini disebabkan karena biaya yang dikeluarkan untuk pembelian insulin jauh lebih mahal dibandingkan obat antidiabetes oral (Fadirah dkk., 2016; Larasanty dkk., 2018; Sholih dkk., 2018). Dengan mengetahui total biaya suatu regimen terapi diharapkan dapat menjadi pertimbangan dalam memilih regimen terapi yang paling optimal untuk pasien. Mengingat pengobatan diabetes mellitus tipe 2 merupakan terapi yang berlangsung seumur hidup.

Jenis biaya lain yang dikeluarkan oleh pasien adalah biaya non medis langsung. Biaya langsung non medis adalah biaya pelayanan non medis yang digunakan untuk membayar pelayanan dibandingkan biaya perawatan medis dan termasuk sumber yang dihabiskan oleh pasien selama transportasi menuju dan dari fasilitas perawatan kesehatan, dan perjalanan tambahan menuju ruang emergensi, serta makanan khusus (Shanchez, 2008). Perhitungan biaya non medis langsung untuk transportasi menggunakan biaya operasional kendaraan di Kota Denpasar.

Pada tabel 3 terlihat bahwa biaya non medis langsung yang dikeluarkan pasien berada pada kisaran Rp. 50.000,- kecuali pada kelompok kombinasi metformin dan glimepiride yaitu Rp. 96.373,-. Yang dikarenakan jarak antara rumah pasien dan rumah sakit lebih jauh dibandingkan pasien lainnya. Biaya non medis tidak langsung adalah biaya yang mengurangi produktivitas (Shanchez, 2008). Pada penelitian ini biaya pengurangan produktivitas dihitung biaya yang diperoleh dari hilangnya produktivitas (tidak masuk kerja). Data pekerjaan pasien dapat dilihat pada tabel 1. Pengumpulan data dilakukan dengan memperhitungkan biaya produktivitas harian pasien berdasarkan slip gaji yang diberikan pasien. Range biaya non medis tidak langsung berkisar antara Rp 264.818,- sampai dengan Rp. 475.954,-.
Berdasarkan data perubahan GDP, GD2PP dan HbA1c pada masing - masing pasien dalam kelompok perawatan, dapat dihitung Persentase effektivitas terapi pada masing - masing kelompok dengan berdasarkan panduan konsensus dari Perkeni (PERKENI, 2015). Terapi selama 3 bulan mmeberikan effektivitas antara $11,11 \%$ sampai dengan $66,66 \%$. Belum ada kelompok obat yang memberikan effektivitas sebanyak $100 \%$ dalam kurun 3 bulan terapi. Monitoring terapi pada pasien DM tipe 2 direkomendasikan dilakukan setelah 3 bulan terapi. Apabila setelah 3 bulan target HbA1c belum tercapai, maka direkomendasikan penyesuaian terapi obat baik dalam pemberian kombinasi atau penggantian jenis obat (Chaudury et al., 2017).

Perhitungan rasio biaya terhadap effektivitas terapi merupakan salah satu cara yang dapat digunakan untuk menilai apakah biaya yang dikeluarkan setara dengan effektivitas yang diperoleh. Untuk jenis intervensi yang setipe, dapat dilakukan perhitungan nilai average cost effectiveness ratio (ACER) (Bang and Zhao, 2012; Edwards, 2011). Namun pada penelitian ini perhitungan ACER tidak dilakukan karena kelompok terapi yang ada sangat variatif, sehingga hanya dilakukan perbandingan antara biaya dan effektivitasnya. Tabel 4 menunjukkan hasil perhitungan rasio effektivitas biaya terapi diabetes mellitus tipe 2 rawat jalan di rumah sakit umum Denpasar. Hasil penelitian menunjukan bahwa biaya terapi yang besar belum tentu memberikan effektivitas yang optimal. Kombinasi Insulin Glargine dan Metformin dengan total biaya terapi Rp. 1.396.088,- ternyata mampu memberikan effektivitas terapi $66,66 \%$. Sedangkan kombinasi $70 \%$ Insulin Aspart Protamin dan $30 \%$ Insulin Aspart dengan total biaya terapi Rp. 3.274.372,memberikan effektivitas terapi 20\%. Pada tabel 4 terlihat bahwa kombinasi terapi metformin dan glimepiride memiliki rasio biaya effektivitas yang terendah sedangkan kombinasi Insulin Aspart dan Insulin Glargine memiliki rasio biaya effektivitas paling tinggi. Dalam pengambilan keputusan terapi obat, selain mempertimbangkan rasionalitas penggunaan obat, tenaga kesehatan juga sebaiknya 
DOI : https://doi.org/10.24843/JFU.2020.v09.i01.p03

pISSN: 2301-7716; eISSN: 2622-4607

Jurnal Farmasi Udayana, Vol 9, No 1, Tahun 2020, 19-25

perlu memperhatikan aspek Analisa farmakoekonomi obat (Edwards, 2011).

\section{KESIMPULAN}

Terdapat 7 kelompok terapi antidiabetes pada pasien DM tipe 2 rawat jalan di rumah sakit umum Denpasar. Berdasarkan pemantauan selama 3 bulan terapi, tingkat effektivitas terapi antidiabetik berkisar antara $11,11 \%$ sampai dengan 66,66\%. Total biaya terapi antidiabetik pada ketujuh kelompok terapi tersebut berkisar antara Rp. 548.094,- sampai dengan Rp. 3.274.372,-. Kelompok terapi dengan rasio biaya per persen effektivitas terendah adalah terapi kombinasi metformin dan glimepiride yaitu dengan biaya Rp 19.184/\% effektivitas dan yang tertinggi adalah terapi kombinasi Insulin Aspart dan Insulin Glargine yaitu Rp. 261.882/\% effektivitas.

\section{UCAPAN TERIMAKASIH}

Terimakasih penulis ucapkan kepada Lembaga Penelitian dan Pengabdian Masyarakat Universitas Udayana dan seluruh pasien yang bersedia mengikuti jalannya penelitian selama 3 bulan.

\section{DAFTAR PUSTAKA}

Bang H, Zhao H. 2012. Average costeffektiveness ratio with censored data. $J$ Biofarm Stat. Vol 22(2): 401-415.

Chaudury A, Duvoor C, Dendi VSR, Kraleti S, Chada A, Ravilla R et all. 2017. Clinical review of antidiabetic drugs: implications for type 2 diabetes mellitus management. Front Endocrinol (Lausanne). 8: 6.

Davies MJ, D'Alessio DA, Fradkin J, Kernan WN, Mathieu C, Mingrone G, et all. 2018. Management of hyperglycemia in type 2 diabetes, A Consensus Report by the American Diabetes Association (ADA) and the European Association for the Study of Diabetes (EASD). Diabetes Care. 41:26692701.
Direktorat Jendral Bina Kefarmasian. 2013. Pedoman Penerapan Kajian Farmakoekonomi. Jakarta: Kemenkes RI.

Downes MJ, Bettington EK, Gunton JE, Turkstra E. 2015. Triple therapy in type 2 diabetes; a systematic review and network meta-analysis. PeerJ. 1461: 1-21.

Edwards C. 2011. Cost-effectiveness analysis in practice. London: IWA Publishing. Halaman 181 197.

Fadirah B, Wahyu Y, Solikah., Qarriy A U. 2016. Analisis biaya terapi diabetes melitus tipe 2 di rumah sakit PKU Muhammadiyah Bantul Yogyakarta. Jurnal Farmasi Sains dan Praktis. Vol 1(2): 11-21.

Harreiter J, Kautzky-Willer A. 2018. Sex and gender differences in prevention of type 2 Diabetes. Front Endocrinol (Lausanne). 9:220.

Larasanty LPF, Sarasmita MA, Putra IGNAD. 2018. Cost effectiveness analysis of of insulin regimen on type 2 diabetes mellitus outpatient in Denpasar municipality. Asian J Pharm Clin Res. Vol 11(1): 89-92.

Luna B, Feinglos MN. 2001. Oral agents in the management of type 2 diabetes mellitus. $A m$ Fam Physician. 63(9):1747-1757.

Marín-Peñalver JJ, Martín-Timón I, SevillanoCollantes C, del Cañizo-Gómez FJ. 2016. Update on the treatment of type 2 diabetes mellitus. World J Diabetes. Vol 7(17): 354-395.

PERKENI. 2015. Konsensus Pengelolaan dan Pencegahan Diabetes Melitus Tipe 2 di Indonesia. Jakarta: Penerbit PERKENI.

Shanchez, LA. 2008. Pharmacoeconomics: principal, methods, and application, dalam: Posey $\mathrm{M}$, editors. Pharmacotherapy: A pathophysiologic approach. United State of America: McGraw-Hill Companies Inc.Halaman1-14.

Sholih MG, Muhtadi A, Saidah S. 2018. Analisis cost illness terapi insulin dan kombinasi insulin-metformin pada pasien diabetes mellitus tipe 2 di salah satu rumah sakit di Bandung. Jurnal Farmasi Klinik Indonesia. Vol 7(1): 10-18.

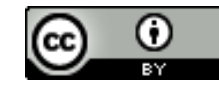

This work is licensed under a Creative Commons Attribution 4.0 International Licens 